\title{
PEMBERDAYAAN ANGGOTA ‘AISYIYAH SE-DAERAH ISTIMEWA YOGYAKARTA DALAM PENGOLAHAN DIAPER BEKAS SEBAGAI CAMPURAN MEDIA TANAM
}

\author{
Inggita Utami $^{1 *}$, Diah Asta Putri ${ }^{2)}$ \\ ${ }^{1)}$ Fakultas Sains dan Teknologi Terapan, Universitas Ahmad Dahlan, \\ email: inggitautami@bio.uad.ac.id \\ ${ }^{2)}$ Fakultas Sains dan Teknologi Terapan, Universitas Ahmad Dahlan, \\ email: diah.putri@bio.uad.ac.id
}

\begin{abstract}
ABSTRAK
Ratusan diaper atau popok sekali pakai bekas memenuhi sungai-sungai yang melintasi Provinsi DI. Yogyakarta (Tribun Jogya, 2018). Permasalahan tersebut memerlukan penyelesaian bersama dimulai dari sumber sampah di tingkat rumah tangga. Tujuan pengabdian kepada masyarakat ini adalah memberikan edukasi dan pelatihan kepada anggota Aisyiyah DI.Yogyakarta dalam mengelola diaper bekas menjadi bahan campuran media tanam. Kegiatan ini diikuti oleh 25 orang pengurus Lembaga Lingkungan Hidup dan Penanggulangan Bencana (LLHPB) Aisyiyah dimana sebagian besar peserta adalah pengurus bank sampah yang tersebar di Provinsi DIY dan belum pernah mendapatkan pelatihan serupa. Hasil kegiatan ini adalah terjadi peningkatan pengetahuan dan keterampilan dari peserta dalam mengelola diaper bekas menjadi campuran media tanam untuk pertumbuhan tanaman tomat. Melalui pelatihan ini peserta yang sebagian besar pengurus bank sampah dapat saling mengajarkan kepada warga RW atau warga desa binaannya di area DIY sehingga jumlah sampah diaper di sungai-sungai dapat berkurang dan langsung terolah di tingkat rumah tangga.
\end{abstract}

Kata kunci: Diaper, Hidrogel, Media tanam

\section{ABSTRACT}

Hundreds of used disposable diapers are wasted in rivers that pass through the DI. Yogyakarta Province (Tribun Jogya, 2018). This problem has to be solved together starting from the source of waste, which is household level. The aim of community service activity is to provide education and training to members of Aisyiyahin DI.Yogyakarta managing used disposable diaper as a mixture of planting media. This activity was attended by 25 members of Lembaga Lingkungan Hidup dan Penanggulangan Bencana (LLHPB) 'AisyiyahDI. Yogyakarta, where most of the participants were Bank Sampah administrators and had never received similar training. After this training was completed, there was an increase in knowledge and skills of the participants for manage hydrogel became mixed-planting media to growup Tomato plants. Through this training, participants who are mostly Bank Sampahadministrators can interact with local residents or their target's villager to make the amount of diaper waste in the DIY's river can be reduced and immediately processed at the household level.

Keywords: Diapers, Hydrogel, Planting media

\section{PENDAHULUAN}

Sampah yang berasal dari daratan kini sudah mengancam ekosistem perairan, salah satunya adalah sampah diaper atau popok sekali pakai. Menurut harian lokal [1], sungai-sungai yang melewati provinsi Daerah Istimewa Yogyakarta (DIY) sudah mengalami darurat diaper dimana jumlahnya mencapai ratusan bahkan ribuan dan tersangkut di jembatan-jembatan sungai. 
Bahan kimia penyusun diaper (polyacrylate granule dan fiber yang berasal dari plastik hidrokarbon, selulosa atau sintetik pulp dan pewangi polychlorine dibenzodioxins) menyebabkan diaper memiliki waktu terdegradasi yang sangat lama yaitu 450 tahun di laut dan 500 tahun di landfill (Tempat Pembuangan Akhir) [2]. TPA Piyungan sebagai basis pembuangan sampah terakhir di Provinsi DI. Yogyakarta juga sudah tidak mampu menampung sampah warganya [3]. Untuk mengurangi dampak negatif dari masalah tersebut, maka pengolahan diaper bekas harus dimulai dari skala rumah tangga baik melalui upaya edukasi, reduce (pengurangan) hingga recycle (daur ulang). Salah satu proses daur ulang diaper bekas adalah menjadikannya media tanam dimana hidrogel superabsorban (SAP) pada diaper berfungsi menyimpan air dalam jumlah banyak [4]. Kegiatan pengolahan ini dirancang dalam bentuk pengabdian kepada masyarakat kepada ibuibu pengurus Lembaga Lingkungan Hidup dan Penanggulangan Bencana (LLHPB) 'Aisyiyah se-DI.Yogyakarta sebagai penggerak kegiatan pelestarian lingkungan hidup di DIY. Tujuan pengabdian kepada masyarakat ini adalah memberikan edukasi dan pelatihan kepada anggota Aisyiyah DIY dalam mengelola gel limbah diaper menjadi bahan campuran media tanam guna mengurangi permasalahan darurat diaper di sungai DIY. Untuk mengoptimalkan penyelesaian masalah sampah diaper ini, kami bermitra dengan seluruh pengurus LLHPB baik di pusat (Pimpinan Wilayah 'Aisyiyah (PWA) DIY) maupun di daerahdaerah (Pimpinan Daerah 'Aisyiyah /PDA) yang tersebar di 5 Kabupaten se-DIY. Tujuan memilih pengurus LLHPB sebagai mitra karena sebagian besar adalah pengurus bank sampah yang tersebar di DIY. Harapannya melalui kegiatan ini, terjadi pengajaran berjenjang terhadap warga di berbagai daerah di DIY dan jumlah diaper bekas di sungai DIY dapat berkurang dan langsung terolah di tingkat rumah tangga.

\section{METODE PELAKSANAAN KEGIATAN}

Kegiatan ini diselenggarakan di bulan Juli hingga Agustus 2019 di kantor Pimpinan Daerah 'Aisyiyah Kota Yogyakarta dimana PDA Kota Yogyakarta ditunjuk sebagai tuan rumah pertemuan tiga bulanan LLHPB seDIY. Terdapat masing-masing lima anggota LLHPB di masing-masing PDA sehingga diharapkan peserta yang hadir minimal berjumlah 25 orang yang tersebar di lima kabupaten di DIY. Secara umum, kegiatan PPM ini terbagi menjadi tiga tahapan. Tahap pertama adalah persiapan alat bahan untuk pengolahan diaper bekas. Kedua adalah penyuluhan materi darurat sampah di Indonesia, dan pelatihan pengolahan diaper bekas. Prakegiatan penyuluhan di mulai peserta dibagikan kuesioner yang berisi pemahaman terhadap darurat sampah dan pengolahannya serta upaya 3R (reduce, reuse, 
recycle) yang sudah dilakukan di tingkat rumah tangga. Ketiga adalah monitoring yang dilakukan di Desa Wirokerten, Bantul dalam kegiatan penanaman tanaman Tomat dengan media tanam campuran limbah diaper.

Terdapat beberapa langkah pengolahan limbah diaper yang dapat dilihat pada gambar 1. Pertama (a), keluarkan isi diaper bekas yang berupa gel kedalam wadah. Kedua (b), siapkan campuran EM4: air gula: air dengan perbandingan 1:1:50 (perbandingan ini mengikuti aturan pemakaian disetiap wadah botol EM4 (Effective Microorganism -4). Ketiga (c), campurkan cairan tersebut dengan gel yang sudah dipisahkan sebelumnya dan diamkan hingga 3-7 hari. Keempat (d), siapkan pot berisi media tanam dan masukan gel diapers tersebut dengan perbandingan 1: 1 lalu aduk hingga merata. Kelima (e), tambahkan tanaman dan penyiraman dapat dilakukan setiap 10 hari sekali.
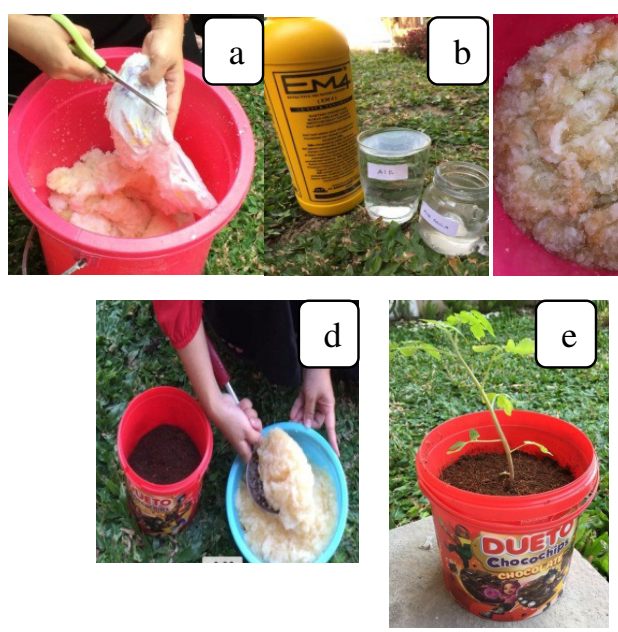

Gambar 1. Tahapan pengolahan gel pada diaper bekas menjadi campuran media tanam

\section{HASIL DAN PEMBAHASAN}

Kegiatan penyuluhan dan pelatihan pengolahan diaper bekas dihadiri oleh 25 orang perwakilan LLHPB 'Aisyiyah yang berasal dari 5 kabupaten yang berbeda, yaitu Kabupaten Kulon progo, Kabupaten Bantul, Kota Yogyakarta, Kabupaten Gunung Kidul, dan Kabupaten Sleman serta 3 orang perwakilan dari LLHPB pusat di wilayah DI. Yogyakarta. Menurut kuesioner yang kami berikan di awal penyuluhan, 100 persen peserta belum mengolah diaper bekas di rumahnya selama ini ataupun belum pernah mendapatkan pelatihan mengenai pengolahan diaper bekas. Terdapat minimal masingmasing satu orang perwakilan peserta dari tiap kabupaten peserta yang menjadi pengurus bank sampah didaerahnya dan berencana akan menerapkan pelatihan ini kepada warga desa binaannya.

Penyuluhan dimulai dengan pemaparan darurat sampah di Indonesia dan kondisi sebagian besar Tempat Pembuangan Akhir (TPA) di Indonesia yang sudah overload dalam menampung sampah (gambar 2). Melalui penyuluhan ini, peserta meningkat pengetahuannya dan memahami kondisi tempat pembuangan akhir sampah, khususnya di TPA Piyungan Yogyakarta. TPA tersebut mendapat limpahan sampah 600 ton setiap harinya dari seluruh wilayah se-DIY. Hasil dari penyuluhan ini juga berdampak pada peningkatan pemahaman peserta akan kondisi 
sungai-sungai yang melintasi DIY yang banyak ditemukan diaper bekas pakai. Hal tersebut diperparah dengan adanya mitos yang masih dianut warga Yogyakarta bahwa tidak boleh membakar diaper atau membuangnya ke tempat sampah karena yakin anaknya tersebut akan sakit. Puluhan meter tinggi tumpukan sampah di TPA Piyungan dan ratusan diaper yang terbuang ke sungai merupakan akumulasi gaya hidup masyarakat di sekitar DIY yang tidak ramah lingkungan dan membuang sampahnya tanpa melakukan upaya 3R (reduce, reuse, recycle).

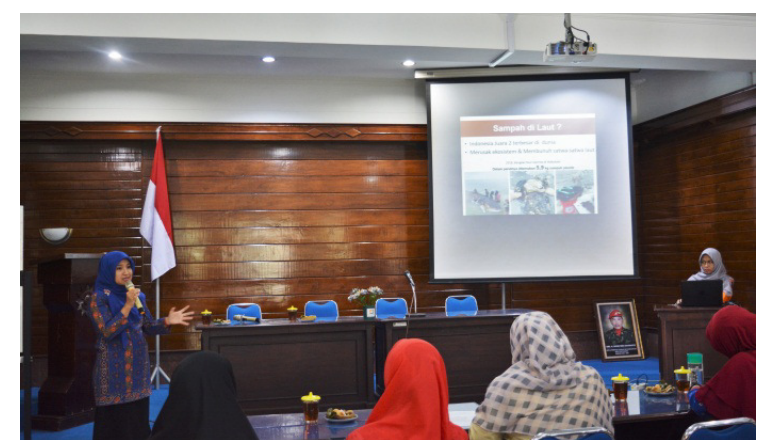

Gambar 2. Penyuluhan tentang darurat sampah di Indonesia

Pelatihan pengolahan diaper bekas (gambar 3) telah meningkatkan pengetahuan dan keterampilan peserta kepada seluruh peserta berdasarkan wawancara langsung diakhir acara. Uji coba selama pelatihan dilakukan dengan menanam tanaman tomat di atas media tanam hasil campuran tanah, kompos, dan gel dari diaper bekas. Hasilnya tanaman tersebut baru terlihat layu setelah 10 hari dari penyiraman di hari pertama. Hal tersebut membuktikan bahwa peran gel dari diaper bekas dalam campuran media tanam ini mampu menjaga kelembaban tanah. [5] telah meneliti bahwa 30,7\% komponen diaper mengandung hidrogel super absorben polimer (SAP). Hidrogel SAP kini telah digunakan sebagai bahan penyimpan air dalam jumlah banyak dan waktu yang lama [6], Hidrogel SAP yang dicampur dengan tanah juga mampu menahan laju pelepasan air dan meningkatkan kemampuan perkecambahan biji dan pertumbuhan semai [7], [8]. Selain itu, EM4 dalam pengolahan diaper bekas digunakan untuk meningkatkan kesuburan dan produktivitas tanah [9]. EM4 merupakan media yang mengandung baktri fermentasi dari Genus Lactobacillus dan Saccharomyces yang mampu memfermentasi bahan organik di dalam tanah menjadi unsur-unsur organik. Selain itu, EM4 mengandung bakteri penambat $\mathrm{N}$ dan bakteri pelarut $\mathrm{P}$.

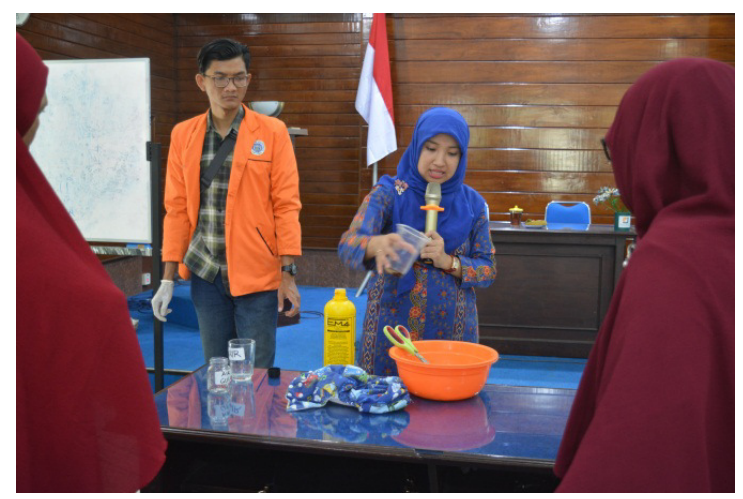

Gambar 3. Pelatihan mengolah diaper bekas menjadi media tanam

Kegiatan evaluasi dan monitoring dilakukan dengan melakukan wawancara kepada perwakilan peserta yang telah menerapkan metode ini baik dirumah maupun di bank sampah yang dibinanya. Salah satu 
peserta yang berasal dari Desa Wirokerten, Bantul menceritakan bahwa pelatihan pengolahan diaper telah diterapkan untuk menanam tanaman tomat dimana penyiraman dilakukan setiap 10 hari sekali.

Keterbatasan dalam kegiatan pengolahan limbah diaper ini adalah kemauan dari peserta yang masih tidak ingin mengolah limbah diaper yang terdapat feses, sehingga ajakan baru sebatas pengolahan diaper bekas yang mengandung urin. Selain itu, tingkat keinginan warga untuk mau mengolah diaper dirasa masih perlu ditingkatkan lagi dengan memberikan pelatihan yang kontinu karena kegiatan pengolahan ini memerlukan usaha dan waktu dalam mengolahnya.

\section{KESIMPULAN}

Kegiatan pengabdian kepada masyarakat melalui pengolahan diaper bekas menjadi campuran media tanam ini dihadiri oleh 25 orang perwakilan LLHPB 'Aisyiyah yang tersebar di 5 kabupaten se-DIY. Penyuluhan dan pelatihan yang dilakukan telah meningkatkan pengetahuan tentang darurat sampah di Indonesia khususnya di Tempat Pembuangan Akhir dan Sungai-sungai, serta meningkatkan keterampilan peserta dalam mengelola hidrogel yang terdapat di diaper bekas menjadi campuran media tanam. Evaluasi dan Monitoring kegiatan dilakukan dilokasi salah satu perwakilan peserta di Desa Wirokerten, Bantul yang telah berhasil menanam tanaman Tomat dengan intensitas penyiraman setiap 10 hari sekali. Kelanjutan dari kegiatan ini diharapkan akan terus di lakukan pada daerah-daerah lainnya sehingga penumpukan sampah diaper bekas baik di TPA maupun di sungai dapat berkurang.

\section{SARAN}

Perlu dilakukan penelitian lanjut yang menguji perbandingan diaper dengan tanah untuk optimalisasi pertumbuhan tanaman, serta pengujian terhadap pertumbuhan tanaman jenis lainnya. Harapannya pendaur ulangan diaper bekas ini dapat teruji pula secara ilmiah untuk area-area yang tidak subur dan kekurangan air.

\section{UCAPAN TERIMAKASIH}

Terima kasih kepada Lembaga Penelitian dan Pengabdian kepada Masyarakat (LPPM) Univeristas Ahmad Dahlan (UAD) untuk dukungan pembiayaan kegiatan PPM ini dan rekan-rekan Biologi UAD untuk dukungan moril selama kegiatan berlangsung.

\section{DAFTAR PUSTAKA}

[1] Tribun Jogya. 2018. Sungai di DIY Darurat Popok. Terbit cetak tanggal 23 Agustus 2018.

[2] Sharhanis, A., Turn, CJ., McLaughray, E., Hartin, K., Hayes, M. (2011). Susainabiliy assessment: seventeen generation diapers vesus diapers. Diperoleh darihttp://www.uvm.edu/ shali/diapers. pdf.

[3] Kompas. 2019. TPST Piyungan Ditutup, Sampah di Beberapa Yogyakarta Menumpuk. Terbit cetak tanggal 27 Maret 2019.

[4] Senna, A. M., Braga, J., Mauro, J. and Botaro, V. R. (2015). Synthesis, Characterization and Application of Hydrogel Derived from Cellulose Acetate as a Substrate for Slow-Release 
NPK Fertilizer and Water Retention in Soil. Journal of Environmental Chemical Engineering, 3(2), 9961002.

[5] Ng, F. S.F., Muthu, S. S., Li, Y. and Hui, P. C.L. (2012). A Critical Review on Life Cycle Assesment Studies of Diapers. Critical Reviews in Environmental Science and Technology, 43(16), 1795-1822.

[6] Qiao, D., Liu, H., Yu, L., Bao, X., Simon, G. P., Petinakis, E. and Chen, L. (2016). Preparation and Chracterization of Slow-Release Fertilizer Encapsulated by StarchBased Superabsorbent Polymer. Carbohydrate Polymers, 147, 146154.

[7] Orikiriza, L. J. B., Agaba, H., Eilu, G.,
Kabasa, J. D. and Worbes, M. (2013).Effects of Hydrogels on Tree Seedling Performance in Temperate Soils Before and After Water Stress. Journal of Environmental Protection, 4, 713-721.

[8] Sanchez-Orozco, R., Beatriz TimoteoCruz, Teresa Torres-Blancas, and Fernando Urena-Nunez. (2017). Valorization of Superabsorbent Polymers from Used Disposable Diapers as Soil Moisture Retainer. International Journal of Research Granthaalayah, 5(4), 105-117.

[9] Ekawandani, N., Alvianingsih. 2018. Efektifitas Kompos Daun Menggunakan EM4 dan Kotoran Sapi. TEDC, 12(2), 145-149. 